\title{
Nuclear medicine services after COVID-19: gearing up back to normality
}

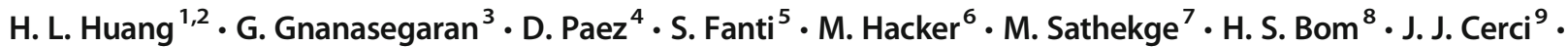

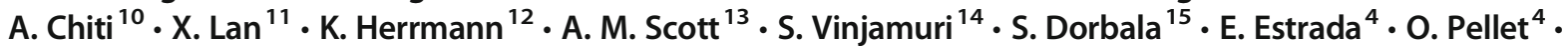 \\ P. Orellana ${ }^{4} \cdot$ N. El-Haj ${ }^{4}$. F. Giammarile ${ }^{4}$ M. Abdel-Wahab ${ }^{4} \cdot$ Jamshed Bomanji $^{1}$
}

Published online: 4 May 2020

(C) Springer-Verlag GmbH Germany, part of Springer Nature 2020, corrected publication 2020

\section{Introduction}

The COVID-19 pandemic is in transition. It may pass or may define a "new normal" over a variable period and might force us to turn our united and undivided attention as a global nuclear medicine community to address the global health of our specialty jointly. The severe acute respiratory syndromecoronavirus-2 (SARS-CoV-2) and the disease it causes (coronavirus disease-2019 or COVID-19 for short) have been the topic of much discussion in the nuclear medicine [1] and radiology [2] literature. Since the first reports of the new virus emerged from China in late December 2019, the World Health Organization (WHO) declared it a public health emergency of international concern on 30 January 2020. WHO declared COVID-19 as a pandemic on 11 March 2020 [3]; it has swept

This article is part of the Topical Collection on Infection and Inflammation

Jamshed Bomanji

jamshed.bomanji@nhs.net

1 Institute of Nuclear Medicine, University College London Hospital, 5th Floor, 235 Euston Road, London, UK

2 Department of Nuclear Medicine and Molecular Imaging, Division of Radiological Sciences, Singapore General Hospita, Bukit Merah, Singapore

3 Royal Free Hospital, London, UK

4 Division of Human Health, International Atomic Energy Agency, Vienna, Austria

5 Department of Oncology, Division of Nuclear Medicine, University of Bologna, Bologna, Italy

6 Department of Nuclear Medicine, Department of Biomedical Imaging and Image-guided Therapy, Medical University of Vienna, Vienna General Hospital, Vienna, Austria

7 Nuclear Medicine Department, University of Pretoria and Steve Biko Academic Hospital, Pretoria, South Africa the globe, with no respect for national boundaries, causing widespread infections, mortality, human suffering, and upending lives in all socioeconomic groups. Governments around the world have rushed to implement measures aimed initially at containing the spread of the virus, but after that, mainly at slowing the COVID-19 spread and mitigating the impact of the virus on local healthcare systems and supply chains. Despite this, there is significant heterogeneity in the degree of success of the various measures, in keeping with differing political, sociological, and economic factors around the world.

Amidst the doom and gloom of the current crisis, however, there are some signs which allow for cautious optimism. There are numerous studies ongoing in the attempt to find an effective vaccine [4] and treatment for COVID-19 [5] and

8 Department of Nuclear Medicine, Chonnam National University, Seoul, South Korea

9 PET/CT Department at Quanta Diagnostics and Therapy, Curitiba, Brazil

10 Humanitas University and Humanitas Research Centre, Milan, Italy

11 Department of Nuclear Medicine, Union Hospital, Tongji Medical College, Huazhong University of Science and Technology, Wuhan, China

12 Department of Nuclear Medicine, Universitätsklinikum Essen, Essen, Germany

13 Department of Molecular Imaging and Therapy, Austin Health, Melbourne, Australia

14 Royal Liverpool University Hospital, Liverpool L7 8XP, UK

15 Division of Nuclear Medicine and Molecular Imaging, Department of Radiology, Brigham and Women's Hospital, Boston, MA, USA 
some early studies showing encouraging data $[6,7]$. There has been a steady fall in the incidence and mortality of COVID-19 [8] at the initial epicenter in Wuhan. With this gradual decrease in numbers, emergently opened hospitals have been closed, and those that were designated as COVID-19 centers have returned gradually to their routine operation. Some semblance of normalcy has returned to life, with the lifting of the lockdown. In other areas, timely and successful measures were implemented, thus allowing for staggering the number of new cases over a more extended period, allowing health systems to care for patients properly without collapsing.

There have been many changes impacting daily life to achieve this effect and, in particular, the provision of healthcare services. Hospitals and other healthcare facilities all over the world were forced to postpone elective procedures, such as surgeries. The treatments of many pathologies had to be adjusted, and many diagnostic procedures were postponed. Nuclear medicine departments needed to adapt their standard procedures to continue providing essential services while minimizing the risk to staff [8], patients [9], and family members, as well as controlling the transmission of the virus, thus allowing essential services in every aspect of nuclear medicine practice, ranging from SPECT/CT, PET/CT, and radionuclide therapy to continue. In a short time, several publications were made available, describing the experience of centers or providing advise $[9,10]$ on how to operate during COVID-19 pandemic [1]. With this collective experience, we are hopefully better prepared to meet the challenges of this or even future pandemics and adjust to the new normal. This pandemic also presents us with a unique opportunity to review our patient flow and optimize or adapt the use of research and development tools such as artificial intelligence.

In the article, we aim to look at changes that should be continued as life returns to some semblance of normalcy. However, this should be cautiously revised as the situation improves. We expect a gradual graded return to normalcy, with restarting of some services first before a staged reversal of the measures. But always with the caveat that this would depend on the situation with regard to the COVID-19 burden. We want to emphasize the critical role of local health experts and national and international guidelines. Each country's stage in the curve may be radically different, even within the different regions of the same country, and there may be very rapid changes in the severity of the COVID-19 outbreak in a matter of days to weeks. One of the measures implemented by most departments based in hospitals is postponing routine elective scans while continuing to provide priority procedures $[11$, 12], to reduce the potential risk of transmission [10].

Inevitably, this will create pressure in scheduling appointments once the threat of COVID-19 reduces. We will discuss possible measures to mitigate this and include a chart of suggested stepwise opening of nuclear medicine services.

\section{Changes implemented due to COVID-19: which should we keep?}

\section{Nuclear medicine staff}

The appropriate use of personal protective equipment (PPE), access to proper sanitation, and the implementation of protocols to screen patients in the waiting area should continue, according to national or local hospital policies. Continued vigilance is prudent, given the potential for second wave infection and future outbreaks remain [9]. The knowledge and learning acquired now will be useful in dealing with any future outbreaks of human-to-human transmitted diseases, if and when they arise. There is acknowledgement of the psychological impact on staff by COVID19 $[13,14]$. Social distancing measures may remain in place or maybe relaxed gradually, depending on the situation. Whatever the case, psychological support for staff should be prioritized, and good communication within the nuclear medicine department should continue even once COVID-19 has abated.

Some nuclear medicine staff may have been split into teams working in separate shifts to minimize the fallout if anyone of them is infected [15]. This shift system can be reversed as the threat of infection reduces, to deal with the expected surge in patient numbers when lockdowns are lifted. Given the ramping up of COVID-19 testing in many countries, easy access to antigen and antibody SARS-CoV-2 testing should be available to all staff groups, especially if the workload increases.

The increasing demands on healthcare generated by the pandemic may have resulted in the redeployment of some nuclear medicine staff to respiratory wards, radiology departments, or even in the intensive care setting. It would be prudent to work closely with human resources and management to ensure the adequate return of this workforce back to home departments before the expected surge in nuclear medicine patient numbers occurs. Preparations should be in place for a possible change in approach if second wave infections with COVID-19 emerge, and flexibility in team and staffing structures are required.

\section{Nuclear medicine patients}

Patients, being encouraged to follow proper hygiene procedures, are something that remains relevant during the transition phase and also in a post-COVID-19 world. While much has been made of the importance of staff having good hygiene to reduce the spread of nosocomial infections, the patients have a role to play as well, with declarations of related symptoms and travel history remaining important. If the waiting areas and appointment processes of the departments have been modified to allow for adequate social distancing, it would seem unnecessary to reverse the excellent work being done 
completely. However, if infection rates decrease, patients' relatives may be allowed to attend the departments together to lend much-needed support.

The wearing of surgical masks by all patients, especially those with symptoms, has been gradually adopted in most countries, particularly those with higher community transmission and larger number of "at-risk" patients (e.g., the elderly or immunocompromised), and has been recommended by numerous editorials [8] and recommendations [1]. As the pandemic evolves and community COVID-19 infection reduces, we will see a gradual easing of this PPE requirement, although in high-risk individuals, this approach will continue for longer. We will need to be vigilant and assess patients in advance of attending for nuclear medicine procedures, and on arrival, to ensure the protection of patients and staff, for some time to come [16].

COVID-19 has resulted in a paradigm shift and pivot toward teleconsultation, particularly for follow-up, stable patients. The benefit would be to reduce exposure of patients coming into the hospital at the expense of the reassurance of face-to-face contact with the treating physician as well as a physical examination. If the situation improves, this could probably be relaxed based on physician and patient preferences and the clinical situation for individual patients.

\section{Nuclear medicine imaging}

Currently, most nuclear medicine departments are reducing patient numbers by cutting down on the appointments given for routine, elective studies, and focusing on more urgent cases. However, this would have created a backlog of cases which, while not urgent, would undoubtedly benefit from having the scans done.

It would be necessary for departments to have protocols in place for deciding the priority of the studies to be done. Particular type of studies could potentially be done on the weekends to reduce the demand for slots on weekdays. We include a sample schedule of how we suggest the gradual reopening of the department can be done (Fig. 1) coded according to a traffic light system and based on the current status of COVID-19 in the local setting. The prioritization of patient studies should be performed in conjunction with referring clinicians, to ensure justified clinical studies are initiated as soon as possible.

Supply chains have come into focus as the COVID-19 pandemic swept the globe. Nuclear medicine is much dependent on global supply chains. Generators in particular and radionuclide therapies are vulnerable to disruption [17] and necessitate careful coordination so as not to waste valuable slots and patient time. The availability of these essential supplies is a prerequisite to the full reopening of services and until these supply chains can be secured may leave departments in a precarious situation with regard to the ability to perform scanning or therapy. Each department should ensure that there is enough availability of tracers and consumables (e.g., kits) before scheduling to clear the backlog of cases.

There have been guidelines suggesting stopping exercise stress for myocardial perfusion imaging $[11,12]$ and the ventilation part of the ventilation-perfusion scan [12] because of the potential for aerosolization. If the COVID-19 threat passes, these may be allowed to continue. However, many departments now use alternatives such as pharmacological stress and perfusion SPECT/CT, and there may be an impetus in the future to evaluate the accuracy of such options in preparation for potential new pandemics or second waves of infection.

\section{Radionuclide therapies}

Most non-urgent therapies have been postponed, although some urgent oncological procedures have been carried out with strict infection control precautions. Good communication with referring clinicians and coordination between healthcare teams is vital to allow for the ramping up of services, efficient use of scarce resources (such as hospital rooms and tracers), and adequate protection of patients, especially those in vulnerable populations such as children or the immunocompromised.

Radionuclide therapy patients are kept in isolation due to restrictions on radiation safety. Resuming services, where currently restricted, is more of a logistical challenge rather than a danger to the health of the patient. In some situations, adapted procedures approved by regulatory authorities during the COVID-19 pandemic (e.g., allowing treatment of patients at home, subject to strict protocols) may potentially be continued if ongoing approval is granted. These arrangements will be dependent on local regulatory agencies, but proactive discussions with these agencies may result in longer term flexibility for outpatient treatments.

\section{Imaging equipment}

In general, nuclear medicine equipment is not portable, and there is not much to be done in terms of changing back to department-based cameras. It remains good practice to ensure cleaning standards are maintained even for routine patients. Quality control (QC) processes have been a vital part of the nuclear medicine department for years and are involved in almost all steps of the patient journey, from preparing the radiopharmaceuticals to ensuring the performance of the gamma or PET cameras. These vital QC measures should continue, even with a surge in caseload, as we cannot afford to compromise clinical quality.

Licensing is country specific and hospital specific. Before exercising any change, it would be prudent to ensure that all 
Fig. 1 Proposed step-wise reopening schedule for a large nuclear medicine department. It should be noted that these are based on consensus only, and responsibility lies with each nuclear medicine department to ensure their written policy adheres to that outlined by National Public Health Guidance or recommendations in their respective countries and institutions. In case of 2nd wave of COVID-19 infection, revert back to "amber" or "red" phase as appropriate. $2 \mathrm{ww}$, 2-week wait; GPs, general medical practitioners; GA, general anesthesia; RAG rating, R (red) A (amber) G (green); ++ slots, additional slots; BAU, business as usual; WFH, work from home
NUCLEAR MEDICINE SERVICES AFTER COVID-19: GEARING UP BACK TO NORMALITY

\begin{tabular}{|c|c|c|}
\hline $\begin{array}{l}\text { RED PHASE: PARTIAL RESTRICTION } \\
\text { LIFT (END OF LOCKDOWN) }\end{array}$ & $\begin{array}{l}\text { AMBER PHASE: PARTIAL LIMITED } \\
\text { RESTRICTIONS }\end{array}$ & GREENPHASE:NEW NORMAL \\
\hline $\begin{array}{l}\text { Patient waiting list triaged for } \\
\text { urgent/ time-sensitive scans } \\
\text { Continue use of PPE during work } \\
\text { Ramp up either per modality or } \\
\text { speciality or both } \\
2 \text { ww/cancer/surgery/ treatment } \\
\text { pathway } \\
\text { Engage referrers, } \\
\text { GPs/clinicians/tertiary centres in } \\
\text { readiness for increased activity } \\
\text { Cancer pathway (elective surgery, } \\
\text { surveillance, treatment response) } \\
\text { Re-establish GA Support } \\
\text { Resume urgent Paediatric \& GA } \\
\text { cases } \\
\text { Review staff deployment with aim } \\
\text { to ramp up and have more staff } \\
\text { locally } \\
\text { Align suppliers in readiness for } \\
\text { increased dose orders \& supplies } \\
\text { Increase staff on site in line with } \\
\text { increased activity } \\
\text { Increase capacity to } 50 \% \\
\text { Ensure auxiliary support services } \\
\text { covered }\end{array}$ & $\begin{array}{l}\text { Increase capacity to } 70-80 \% \\
\text { Continue use of PPE during work } \\
\text { Staff engagement for routine 9-5 } \\
\text { shifts } \\
\text { Expand communications to all } \\
\text { referrers } \\
\text { Ongoing RAG rating for referrals } \\
\text { Review pathways and new ways } \\
\text { of working to inform whether } \\
\text { current practice is optimal } \\
\text { Invite transport patients } \\
\text { PET cameras to function full } \\
\text { capacity } \\
\text { Open up SPECT-CT camera } \\
\text { capacity } \\
\text { Resume complex procedures } \\
\text { (e.g., ICTAL HMPAO service) } \\
\text { Continue to expand on Paediatric } \\
\text { \& GA cases } \\
\text { Align suppliers in readiness for } \\
\text { increased dose orders \& supplies } \\
\text { Active daily tracking of DNA \& } \\
\text { Cancellations } \\
\text { Construct statement for Patient } \\
\text { reassurance for telephone } \\
\text { bookings } \\
\text { Forecast planning to complete } \\
\text { backlog } \\
\text { Instigate retrospective audits and } \\
\text { review requirement for updates on } \\
\text { pathways, activities } \\
\text { Prepare for full-service activation }\end{array}$ & $\begin{array}{l}\text { Increase capacity to } 90 \% \\
\text { Optimise workforce } \\
\text { Inform patients we are offering ++ } \\
\text { slots } \\
\text { Plan for outsourced work to come } \\
\text { back to Dept } \\
\text { BAU Communication to suppliers } \\
\text { /stakeholders } \\
\text { Reinstate all routine } \\
\text { services } \\
\text { Implement timetable for backlog } \\
\text { completion } \\
\text { Reintroduce training, education, } \\
\text { etc. as normal. } \\
\text { Devise \& agree contingency plans } \\
\text { with Suppliers when we hit second } \\
\text { wave. } \\
\text { Engage staff so everyone aware } \\
\text { and responsive } \\
\text { Ensure pathways updated and } \\
\text { easily accessible. } \\
\text { Ensure sufficient PPE. } \\
\text { Continue PPE use during work in } \\
\text { line with local policy } \\
\text { Create project list for activities that } \\
\text { can be done off-site. } \\
\text { Resume research scans }\end{array}$ \\
\hline
\end{tabular}

staff involved in patient care be appropriately licensed according to local guidelines.

\section{Nuclear medicine continuing medical education and continuing professional development}

The growing use of zoom, WebEx, and other teleconferencing software highlights how the advances in technology have allowed some services such as teaching conferences and multidisciplinary team meetings to continue in the setting of COVID-19. It is likely that the time savings of using such software to meet, from the convenience of one's office or home, would be continued in the future. Major conferences planned for 2020 have been converted to virtual meetings, and this approach is likely to become a major part of nuclear medicine conferences in the future.
In some countries, social distancing measures were implemented to reduce the number of people involved in social gatherings, for example, restricting groups to no more than 50 , then 10 , and then two people. Hopefully, this can be gradually reversed, and larger conferences that allow the making of professional contacts and the exchange of ideas can be restarted.

\section{Incidental chest imaging findings}

It remains a good practice to scrutinize the $\mathrm{CT}$ component of hybrid imaging studies. Knowledge of incidental chest imaging findings of COVID-19 will continue to be necessary, in case of a reemergence of the SARS-CoV-2 or new atypical instances of viral pneumonia [18]. 
Fig. 2 Suggested checklist for recovery phase post-COVID-19 pandemic. It should be noted that these are based on consensus only, and responsibility lies with each nuclear medicine department to ensure their written policy adheres to that outlined by National Public Health Guidance or recommendations in their respective countries and institutions

\begin{tabular}{|c|c|}
\hline HUMAN RESOURCE & PATIENT FLOW \\
\hline $\begin{array}{l}\text { 1. Review staff numbers including those } \\
\text { who might have been redeployed } \\
\text { elsewhere } \\
\text { 2. Mental wellbeing of all staff categories } \\
\text { prioritised and supported } \\
\text { 3. Address any refresher training needs } \\
\text { 4. Well established regular communications } \\
\text { to team } \\
\text { 5. Access to antigen and antibody testing } \\
\text { for COVID-19 where appropriate } \\
\text { 6. Appropriate PPE availability for all key } \\
\text { workers in departments } \\
\text { 7. Additional staff to cover backlog / } \\
\text { possible surge in referrals in recovery } \\
\text { phase }\end{array}$ & $\begin{array}{l}\text { 1. Review patient flow through departments } \\
\text { to take account of relevant distancing } \\
\text { guidelines for tested/ non-tested patients } \\
\text { for short and medium term } \\
\text { 2. Review mix between in-patient and out- } \\
\text { patient procedures } \\
\text { 3. Review layout of department to address } \\
\text { patient flow } \\
\text { 4. Review whether some medical } \\
\text { consultations may be converted to } \\
\text { teleconsultations on long-term basis } \\
\text { 5. Ensure continued lines of communication } \\
\text { with referrers and management } \\
\text { 6. Address any queries from patients in } \\
\text { reasonable timeframe }\end{array}$ \\
\hline EQUIPMENT & RADIOPHARMACEUTICALS \& LICENCES \\
\hline $\begin{array}{l}\text { 1. Review quality assurance/quality control } \\
\text { of all key equipment's } \\
\text { 2. Review service contracts of key } \\
\text { equipment's } \\
\text { 3. Review equipment replacement policy } \\
\text { 4. Review breakdown/weekend repair } \\
\text { services in case of surge in referrals in } \\
\text { recovery phase } \\
\text { 5. Review practicality and logistics of } \\
\text { continuing to use remote working } \\
\text { stations }\end{array}$ & $\begin{array}{l}\text { 1. Ensure continued liaison with } \\
\text { radiopharmacies to address range and } \\
\text { breadth of supplies required to address } \\
\text { possible surge in referrals } \\
\text { 2. Review all key individual and site- } \\
\text { specific licences to ensure continued } \\
\text { regulatory compliance } \\
\text { 3. Approach legislative bodies with } \\
\text { proposals for change if temporary } \\
\text { changes post COVID-19 need to be } \\
\text { continued beyond pandemic }\end{array}$ \\
\hline EMERGENCY SUPPLIES & TEACHING, TRAINING \& RESEARCH \\
\hline $\begin{array}{l}\text { 1. Plan for emergency stocks of key } \\
\text { equipment's in line with local policy } \\
\text { 2. Update business continuity and } \\
\text { emergency preparedness plans }\end{array}$ & $\begin{array}{l}\text { 1. Enable process to restart any stalled } \\
\text { research and development activity due to } \\
\text { pandemic } \\
\text { 2. Enable process to restart journal clubs } \\
\text { 3. Enable process to address any new } \\
\text { research questions arising out of recent } \\
\text { pandemic } \\
\text { 4. Investigate use of artificial intelligence to } \\
\text { increase efficiencies }\end{array}$ \\
\hline
\end{tabular}

\section{Preparing for a surge in caseload}

We have included a stepwise chart (Fig. 1) of how we would reopen a large nuclear medicine department. We have divided the interventions as (a) "red" phase, with a partial lift of the measures initially implemented, to coincide with the government's lifting of the lockdown; (b) "amber" phase would happen after the "red" phase ends (approximately 2-3 weeks subject to local regulatory guidance), allowing a graded step-up of capacity to $70-80 \%$; and (c) "green" phase is almost near to normal with $90 \%$ capacity, increased staff capacity, and scheduling less urgent routine studies. If the situation worsens or a second peak happens, there is also the possibility of reversing the chart, going back to "amber" or "red" status in an orderly fashion.
Before fully reopening the departments, it would be prudent to ensure all preconditions are in place. Hence, we have included a proposed checklist (Fig. 2) as a guide, given that local regulations may sometimes be different.

\section{Conclusion}

COVID-19 has resulted in severe disruption in many aspects of life, including the nuclear medicine departments. We hope that with the improving situation in many countries, life may slowly resume normalcy. It would be prudent to plan and execute a plan to return to "business as usual" in nuclear medicine, recognizing that flexibility in transitioning from current operations is required to avoid a "flood" of patients. 
We should adapt quickly to the changing landscape, shifts in referral patterns, and work accordingly.

\section{Compliance with ethical standards}

Conflict of interest The authors declare that they have no conflict of interest.

Guarantor Not applicable.

Statistics and biometry No complex statistical methods were necessary for this paper.

Informed consent Not applicable.

Ethical approval Institutional Review Board approval was not required because the paper is an Editorial.

Study subjects or cohorts overlap Not applicable.

Methodology Not applicable.

\section{References}

1. Paez D, Gnanasegaran G, Fanti S, et al. COVID-19 pandemic: guidance for nuclear medicine departments. Eur J Nucl Med Mol Imaging. 2020. https://doi.org/10.1007/s00259-020-04825-8

2. Kanne JP, Wi M, Little BP, Chung JH, Elicker BM, Ketai LH. Essentials for radiologists on COVID-19: an update-radiology scientific expert panel.

3. Kanne JP, Little BP, Chung JH, Elicker BM, Ketai LH. Essentials for Radiologists on COVID-19: An Update-Radiology Scientific Expert Panel. Radiology. 2020;27:200527. https://doi.org/10. 1148/radiol.2020200527.

4. Ahmed SF, Quadeer AA, McKay MR. Preliminary identification of potential vaccine targets for the COVID-19 coronavirus (SARSCoV-2) based on SARS-CoV immunological studies. Viruses. 2020;12(3). https://doi.org/10.3390/v12030254.

5. Zhang L, Liu Y. Potential interventions for novel coronavirus in China: a systematic review. J Med Virol. 2020;92(5):479-90. https://doi.org/10.1002/jmv.25707.

6. Huang $\mathrm{C}$, Wang Y, Li X, et al. Clinical features of patients infected with 2019 novel coronavirus in Wuhan, China. Lancet. 2020;395(10223):497-506. https://doi.org/10.1016/S01406736(20)30183-5.

7. Liu F, Xu A, Zhang Y, et al. Patients of COVID-19 may benefit from sustained lopinavir-combined regimen and the increase of eosinophil may predict the outcome of COVID-19 progression. Int J Infect Dis. 2020. https://doi.org/10.1016/j.ijid.2020.03.013.

8. Liang Huang H, Allie R, Gnanasegaran G, Bomanji J. COVID19nuclear medicine departments, be prepared! Nucl Med Commun. 2020;2020:297-9. https://doi.org/10.1097/MNM. 0000000000001183 .

9. Leung K, Wu JT, Liu D, Leung GM. First-wave COVID-19 transmissibility and severity in China outside Hubei after control measures, and second-wave scenario planning: a modelling impact assessment. Lancet. 2020;0(0):1382-1393. https://doi.org/10.1016/ S0140-6736(20)30746-7.

10. Assadi M, Gholamrezanezhad A, Jokar N, Keshavarz M, Picchio M, Seregni E, Bombardieri E, Chiti A. Key elements of preparedness for pandemic coronavirus disease 2019 (COVID-19) in nuclear medicine units. Eur J Nucl Med Mol Imaging. 2020. https://doi. org/10.1007/s00259-020-04780-4.

11. Skali H, Murthy VL, Al-Mallah MH, et al. Guidance and best practices for nuclear cardiology laboratories during the coronavirus disease 2019 (COVID-19) pandemic: an information statement from ASNC and SNMMI. 2020. https://zenodo.org/record/ 3738020\#.Xq73JZnTVPa.

12. COVID-19: ACR statement on nuclear medicine ventilation scans American College of Radiology. https://www.acr.org/Advocacyand-Economics/ACR-Position-Statements/COVID19-NuclearMedicine-Ventilation-Scans. Accessed April 23, 2020.

13. Xiang YT, Yang Y, Li W, Zhang L, Zhang Q, Cheung T, Ng CH. Timely mental health care for the 2019 novel coronavirus outbreak is urgently needed. Lancet Psychiatry. 2020;7(3):228-9. https://doi. org/10.1016/S2215-0366(20)30046-8.

14. Duan L, Zhu G. Psychological interventions for people affected by the COVID-19 epidemic. Lancet Psychiatry. 2020;7(4):300-2. https://doi.org/10.1016/S2215-0366(20)30073-0.

15. Lam WW, Loke KS, Wong WY, Ng DC. Facing a disruptive threat: how can a nuclear medicine service be prepared for the coronavirus outbreak 2020? Eur J Nucl Med Mol Imaging https://doi.org/10. 1007/s00259-020-04790-2

16. Czernin J, Fanti S, Meyer PT, et al. INuclear Medicine Operations in the Times of COVID-19: Strategies, Precautions, and Experiences. J Nucl Med. 2020;61(5):626-629. https://doi.org/10. 2967/jnumed.120.245738.

17. Cutler CS, Schwarz SW. Diversification in the supply chain of 99Mo ensures a future for 99mTc. J Nucl Med. 2014;55(7):120813. https://doi.org/10.2967/jnumed.113.131953.

18. Albano D, Bertagna $\mathrm{F}$, Bertolia $\mathrm{M}$, et al. Incidental Findings Suggestive of Covid-19 in Asymptomatic Patients Undergoing Nuclear Medicine Procedures in a High Prevalence Region. J Nucl Med. 2020:jnumed.120.246256. https://doi.org/10.2967/ jnumed.120.246256.

Publisher's note Springer Nature remains neutral with regard to jurisdictional claims in published maps and institutional affiliations. 